\title{
Sex and Gender Roles in Relation to Mental Health and Allostatic Load
}

\author{
Robert-Paul Juster, PhD, Jens C. Pruessner, PhD, Alexandra Bisson Desrochers, BSc, \\ Olivier Bourdon, BSc, Nadia Durand, DEC, Nathalie Wan, MA, Valérie Tourjman, MD, \\ Edouard Kouassi, PhD, Alain Lesage, MD, and Sonia J. Lupien, PhD
}

\begin{abstract}
Objectives: Beyond male/female binaries, gender roles represent masculine and feminine traits that we assimilate and enact throughout life span development. Bem proposed that "androgynous" individuals adeptly adapt to different contexts by alternating from a strong repertoire of both masculine and feminine gender roles. By contrast, "undifferentiated" individuals may not adapt as well to social norms because of weak self-endorsed masculinity and femininity.
\end{abstract}

Methods: Among 204 adults (mean [standard error] age $=40.4$ [0.9] years; 70\% women) working in a psychiatric hospital, we hypothesized that androgynous individuals would present better mental health and less physiological dysregulations known as allostatic load (AL) than undifferentiated individuals. AL was indexed using 20 biomarkers using the conventional "all-inclusive" formulation that ascribes cutoffs without regard for sex or an alternative "sex-specific" formulation with cutoffs tailored for each sex separately while controlling for sex hormones (testosterone, estradiol, progesterone). Well-validated questionnaires were used.

Results: Independent of sex, androgynous individuals experienced higher self-esteem and well-being and lower depressive symptoms than did undifferentiated individuals. Men manifested higher AL than did women using the all-inclusive AL in$\operatorname{dex}\left(p=.044, \eta_{\mathrm{P}}^{2}=0.025\right)$. By contrast, the sex-specific AL algorithm unmasked a sex by gender roles interaction for AL $\left(p=.043, \eta_{\mathrm{P}}^{2}=0.048\right)$ : with the highest AL levels in undifferentiated men. Analysis using a gender index based on seven gendered constructs revealed that a greater propensity toward feminine characteristics correlated only with elevated sexspecific AL $(r=0.163, p=.025)$.

Conclusions: Beyond providing psychobiological evidence for Bem's theory, this study highlights how sex-specific AL formulations detect the effects of sociocultural gender.

Key words: gender roles, androgyny, mental health, cortisol, allostatic load, gender schema theory.

\section{INTRODUCTION}

$T^{1}$ he sexes are not equal in their unique susceptibilities to specific stress-related diseases. For example, women experience more psychosocial stressors and protracted sick leave due to mental health problems, whereas men are more prone to physical stressors and ultimately earlier mortality $(1,2)$. Trends in North America reveal that women are increasingly dying of cardiovascular disease (3), whereas rates among men are declining or remaining stable (4). Although heart health was once viewed predominantly as a men's health issue, incidences of cardiovascular disease are increasing for women worldwide $(1,5)$. To understand how "sex-specific" diseases like cardiovascular disease, mood disorders, somatic complaints, and muscular-skeletal disorders can change throughout history (6), scientists must identify the sociocultural factors that modulate disease susceptibilities. Beyond one's sex, within-sex variations related to gender

$\mathbf{A L}=$ allostatic load, $\mathbf{A N C O V A}=$ analysis of covariance, $\mathbf{A U C g}=$ area under the curve with respect to ground, $\mathbf{C I}=$ confidence intervals, PCA = principal component analysis

From the Centre for Studies on Human Stress (Juster, Desrochers, Bourdon, Durand, Wan, Lupien), Montreal, Quebec, Canada; Research Centre of the Institut universitaire en santé mentale de Montréal (Juster, Durand, Wan, Tourjman, Kouassi, Lesage, Lupien), Montreal, Quebec, Canada; Integrated Program in Neuroscience (Juster, Pruessner) and Departments of Psychiatry and Psychology (Pruessner), McGill University, Montreal, Quebec, Canada; Research Centre of the Douglas Mental Health University Institute (Pruessner, Desrochers), Montreal, Quebec, Canada; Department of Psychology (Desrochers), Université du Québec à Montréal, Montreal, Quebec, Canada; Departments of Medicine and Medical Specialties (Kouassi) and Psychiatry (Tourjman, Lesage, Lupien), Université de Montréal, Montreal, Quebec, Canada.

Address correspondence and reprint requests to Sonia J. Lupien, PhD, Centre for Studies on Human Stress, 7401 Hochelaga, Pavillion Louis Riel, Unit 226, Montreal, Quebec, Canada H1N 3M5. E-mail: sonia.lupien@umontreal.ca 
could further explain why these disease trajectories are inconsistently sex-specific (7).

Gender represents a spectrum of sociocultural roles, identities, and orientations that are distinct from one's biological sex determined by genes, anatomy, gonads, and hormones $(8,9)$. Gender socialization leads to the development of gender roles or personality stereotypes we assimilate and endorse via the enactment of masculine or feminine behaviors (10). In the 1970s, Bem proposed that masculine and feminine gender roles are two independent yet complementary constructs. Masculinity was viewed as an instrumental orientation and cognitive focus on action, whereas femininity was viewed as an expressive orientation and affective concern for the welfare of others (11). The process whereby society defines and transforms gender roles is referred to as gender typing that modulates cognitivebehavioral processes (12).

In evolving our gender schema throughout life span development, we encode and process gender-based information and systematically appropriate sex-specific behaviors consistent with our gender identity representing the sex we see ourselves as (12). Bem argued that "gender-typed" individuals are those that rigidly conform exclusively to their masculine or feminine schemas at the detriment of their psychological well-being. For example, self-identification as a hypermasculine heterosexual man might lead to distress when enacting cross-gender behaviors associated with femininity (e.g., nurturing, sensitive). The paragons of mental health according to Bem were "androgynous" individuals who could effectively navigate both masculine and feminine behaviors in different contexts. By contrast, "undifferentiated" individuals would show below-average propensities of either masculinity or femininity that she proposed was the most maladaptive profile (13). Although immensely influential in the psychosocial literature, Bem's gender schema theory (12) and proposal of androgyny versus undifferentiation has yet to be supported using comprehensive biological approaches to measure stress.

In theory, biological sex and psychosocial gender influence threat processing and therefore stress physiology (2). For both sexes, stressful circumstances lead to the malfunctioning of the stress hormone cortisol that contributes over time to disease by recalibrating interconnected neuroendocrine, immune, metabolic, and cardiovascular functions (14). Allostatic load (AL) embodies this multisystemic "wear and tear" that chronic stress exerts in synergy with unhealthy behaviors (15). AL algorithms index the number of dysregulated biomarkers reaching subclinical cutoffs based on a given sample's distribution that are predictive of disease (16). Indeed, elevated AL indices are linked to numerous antecedents (e.g., poor social networks, workplace stress, life-style behaviors) and consequences (e.g., mortality, cardiovascular disease, psychiatric symptoms) (17). Although aging is the strongest correlate of increased AL, sex differences are inconsistent (18). Critically, few studies ascribe sex-specific cutoffs when calculating AL (19) or none have taken consideration of sex hormones (e.g., testosterone, estrogen) fundamental to stress physiology (20). To further understand sex differences in AL, researchers must endeavor to demarcate gender-based modulation further while accounting for one' sex and vast withinsex differences in basal sex hormone functioning (8).

In the current study, we propose that biological sex and sociocultural gender interactively influence $\operatorname{AL}(8,21)$. Research shows that extremely traditional or hegemonic masculine gender-typed individuals (e.g., hostile, dictatorial) exhibit coronary-prone behaviors (e.g., inhibited emotional expression, lack of empathy, homophobia) that overlap with hostility that is linked to elevated $\operatorname{AL}(22,23)$. To date, however, little is known of the impact of gender-based factors on AL despite significant overlap with interconnected factors. For example, several of the salubrious effects thus far identified in the AL literature differ according to sex specifically for sociocultural constructs such as spousal support, social networks, and religiousity/spirituality (24-27) that are related to gender.

Applying a sex- and gender-based analysis (28) of AL could illuminate how variations in biological sex and psychosocial gender relate to health outcomes. In a pilot study of 30 workers, we found that increased masculine gender roles relative to feminine gender roles were associated with high AL for both sexes and with psychosomatic complaints among masculine women (29). In separate reports of gendered sexual orientation, we found that gay/bisexual men had lower stress reactive cortisol in response to a psychosocial stressor, lower AL, and lower depressive symptoms than did heterosexual men, whereas lesbian/bisexual women had higher reactive cortisol and trending depressive symptoms than did heterosexual women $(30,31)$. These effects were influenced by within-group differences whereby sexual minorities who had completely disclosed or "come out" manifested lower morning cortisol concentrations and psychiatric symptoms than did those who were not fully disclosed. Collectively, these studies demonstrate that measuring sex, gender roles, and sexual orientation reveal withinsex associations that are impossible to discern by assessing sex solely as a binary classification (32).

Measuring gender is complex (33). Recently, in an effort to pin-point the influence of sex and/or gender factors vis-à-vis acute coronary syndrome, Pelletier et al. (34) innovated a composite measure of gender comprising various psychosocial variables such as primary earner status, personal income, number of hours per week doing housework, level of stress at home, and both Bem masculinity and femininity scores. They found that feminine gender was associated with the heaviest burden of cardiovascular disease risk factors (e.g., hypertension, depressive symptoms, smoking) independent of sex (34). Sex and 
gender therefore represent overlapping yet distinct phenomena that must be delineated to better predict diseases more prevalent in one sex or the other at a given historical period. Our aim in this study is to assesses sex and gender categorically and continuously vis-à-vis mental health and AL.

\section{Research Question and Hypothesis}

Building upon our previous sex/gender research (29-31), the goal of the current study was to apply a comprehensive sex- $b y$ gender-based analysis of AL and mental health in a large-sample of healthy workers. In accordance with theoretical work on gender roles (11-13) and the rich biological literature on measuring stress (35), we hypothesized that androgynous individuals would self-report higher selfesteem, well-being, and social support as well as lower symptoms of depression and AL levels than undifferentiated individuals, whereas masculine and feminine gender types were expected to fall in between androgynous and undifferentiated individuals. AL was indexed using 20 neuroendocrine, immune, metabolic, and cardiovascular biomarkers according to the (1) conventional "all-inclusive" formulation that ascribes cutoffs without regard for sex or an alternative (2) "sex-specific" formulation with cutoffs tailored to men and women separately. In accordance, we expected AL to only differ between men and women when using the allinclusive formulation or to differ according to gender roles when using a sex-specific formulation. Lastly, we followed the approach by Pelletier et al. (34) and calculated a gender index using principal component analysis (PCA) and logistic regression to respectively reduce seven gender factors into components that we expected would correlate only to the sex-specific AL index.

\section{METHODS}

\section{Participants}

Participants included 60 men and 144 women (cycling: $n=55$; contraceptive: $n=47$; postmenopausal: $n=42$ ) recruited from the employees of the Institut universitaire en santé mentale de Montréal as part of a larger study (36). This is the largest psychiatric hospital in Québec with 1546 employees that are predominantly women $(65 \%)$ from diverse professions. To achieve a medium to large effect size, an a priori power analysis suggested that we achieve a total sample size of 159 participants.

From a pool of 295 prospects, the final distribution of participants is $n=204$. Note that those that did not participate were not lost due to exclusion criteria. Of those that did participate, occupations are as follows: clinical services $(n=61 ; 29.9 \%)$, administration $(n=35 ; 17.2 \%)$, research $(n=28 ; 13.7 \%)$, social integration $(n=23 ; 11.3 \%)$, professional services $(n=20 ; 9.8 \%)$, maintenance $(n=22 ; 10.8 \%)$, general direction $(n=9$; $4.4 \%)$, and human resources $(n=6 ; 3.0 \%)$. Occupational status was coded based on professions using the Nam-Powers-Boyd method (37) previously used by our group (19). Table 1 lists the sample's descriptive statistics for demographics, interpersonal, health behaviors, and physical/mental health domains that were assessed for group differences according to sex and gender roles separately.

\section{General Protocol}

This study was approved by the local research ethics board of the Institut universitaire en santé mentale de Montréal and adheres to the Declaration of Helsinki. Testing was conducted by two women (N. D. and A. B. D.) and two men (R. P. J. and O. B.) between October 2011 and December 2012 at the Centre for Studies on Human Stress (Montreal, Quebec, Canada). Access to the participant pool was enabled by hospital administrators who allowed workers to participate during their working hours without prejudice and in full confidentiality. In partnership with our communications department, recruitment was promoted via conferences, intranet advertisements, large banners, face-to-face visits to units, and word of mouth. Prospects were instructed to contact our laboratory for a 15 -minute screening interview before scheduling appointments.

During their first laboratory visit between 1300 and 1800 hours (arrival time: mean $=1335$ hours, standard error $[\mathrm{SE}]=0: 03$ ) that lasted approximately 90 minutes, participants were a) requested to read and sign the consent form; b) instructed to provide saliva samples every 10 minutes at seven occasions throughout the visit to assess stress reactive cortisol; c) completed a cognitive task (data not reported here); d) exposed to the Trier Social Stress Test (38), a popular laboratory-based psychosocial stressor; e) instructed in the use of our Internet-based questionnaire system; f) provided instructions for diurnal salivary collection to assess day-to-day variations in cortisol; and finally g) debriefed. Between visits, participants collected saliva samples at home and completed electronic questionnaires that took approximately 45 minutes to complete.

During their second visit scheduled between 0800 and 1100 hours (arrival time: mean $=0854$ hours, $\mathrm{SE}=0: 05)$ that lasted approximately 15 minutes, participants returned materials and partook in a blood draw by a licensed nurse. Upon blood draw and physical examination, a Continental breakfast was provided to break a 12-hour fast. Participants received $50 \$ C A D$ as compensation.

\section{Questionnaires}

Questionnaires were completed electronically via a secured Web-based questionnaire interface called the Studies Web Automation Tool that meets all the requirements for conducting ethical and secure encryption of Webbased questionnaires.

\section{Gender Roles}

The 60-item Bem Sex Role Inventory $(11,39)$ was used to measure gender roles. This instrument uses a 7-point Likert scale ranging from 1 (never or almost never true) to 7 (always or almost always true) for masculine (e.g., ambitious, dominant, self-reliant) and feminine (e.g., affectionate, gentle, understanding) items. Original psychometrics demonstrated acceptable internal consistency for the masculinity subscale $(\alpha=.81)$ and femininity subscale $(\alpha=.86)$ as well as strong retest reliability ranging from $r$ values $=0.89$ to 0.93 . In the present study, reliability analyses revealed acceptable internal consistency for the masculinity subscale (women: $\alpha=.78$; men: $\alpha=.79$ ), albeit weaker reliability for the femininity subscale (women: $\alpha=.61$; men: $\alpha=.60$ ). Men scored higher on masculinity $\left(p<.001, \eta_{\mathrm{P}}^{2}=0.113\right)$, whereas women scored higher on femininity $\left(p<.001, \eta_{\mathrm{P}}^{2}=0.139\right)$.

In a revised coding system aimed at assessing psychological androgyny (13), Bem recommended dichotomizing masculinity and femininity subscales to create four gender-role classifications: a) masculine if only the masculinity score ranked above the median, b) feminine if only the femininity score ranked above the median, c) androgynous if both the masculinity and femininity scores ranked above the respective medians, and d) undifferentiated if both the masculinity and femininity scores ranked below the respective medians. We adopted this approach using sex-specific medians for the masculinity subscale (4.6 for women and 4.8 for men) and femininity subscale (6.1 for women and 5.9 for men). In accordance, sex-specific gender-role groups are distributed as follows: masculine-typed (43 women 


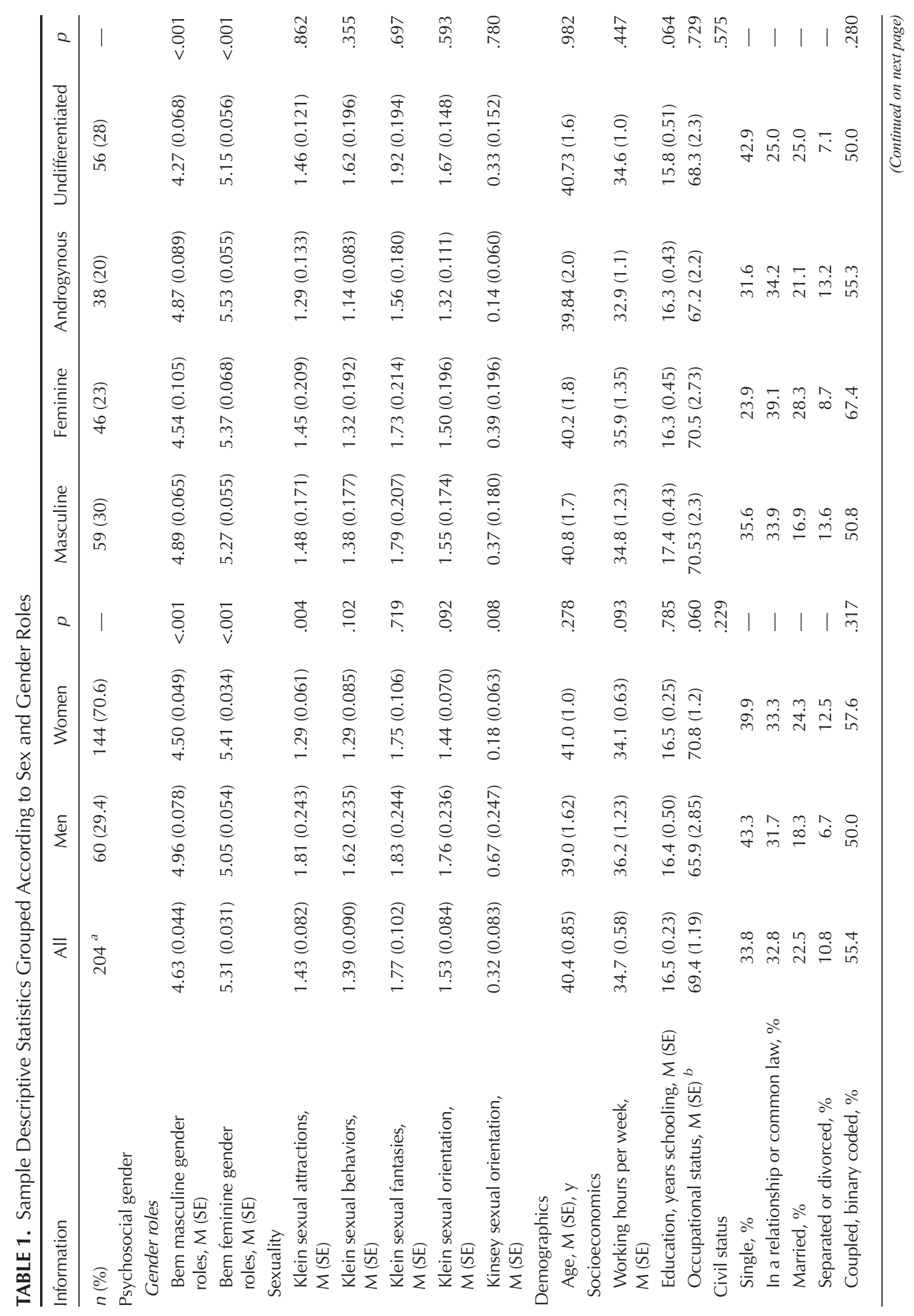




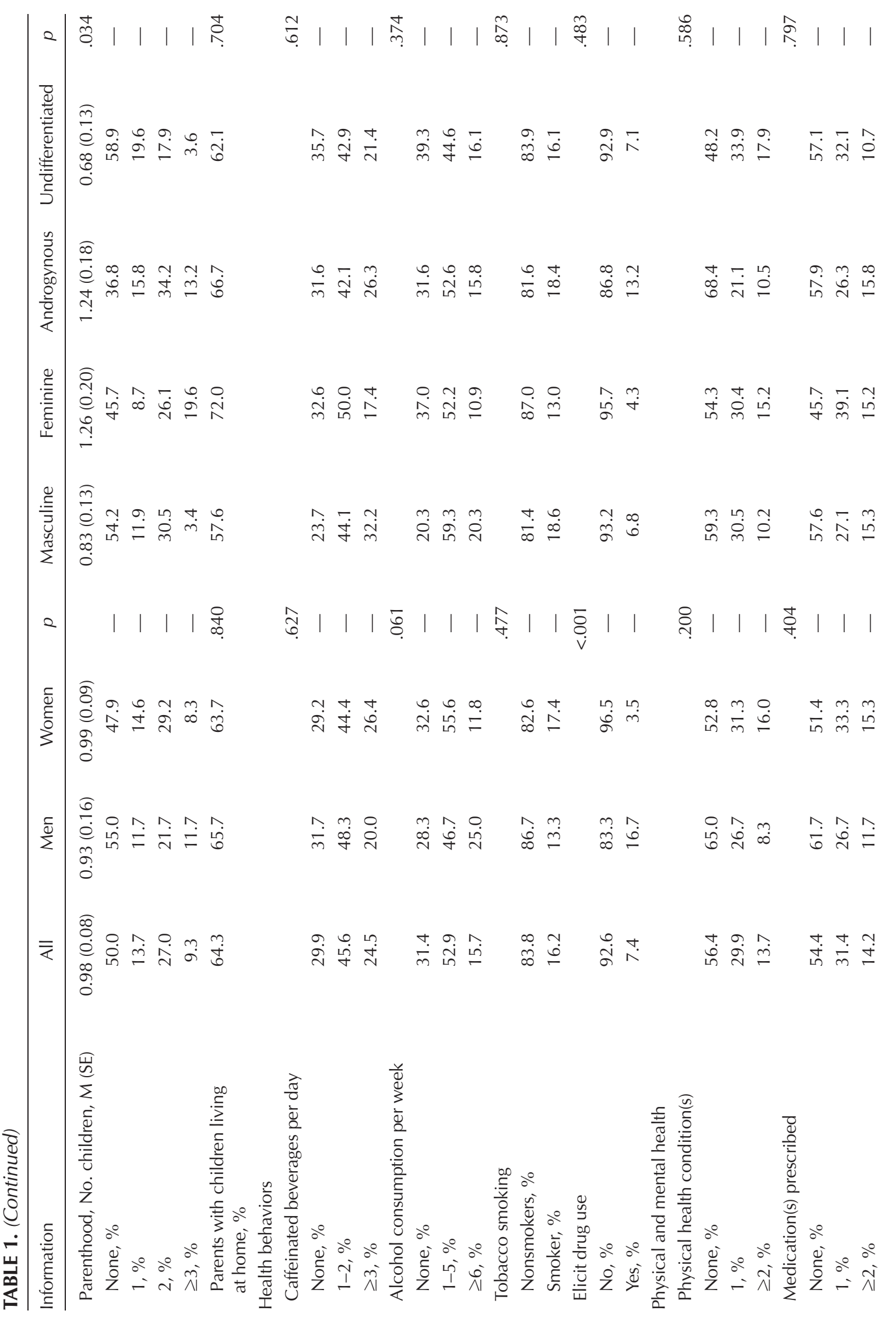




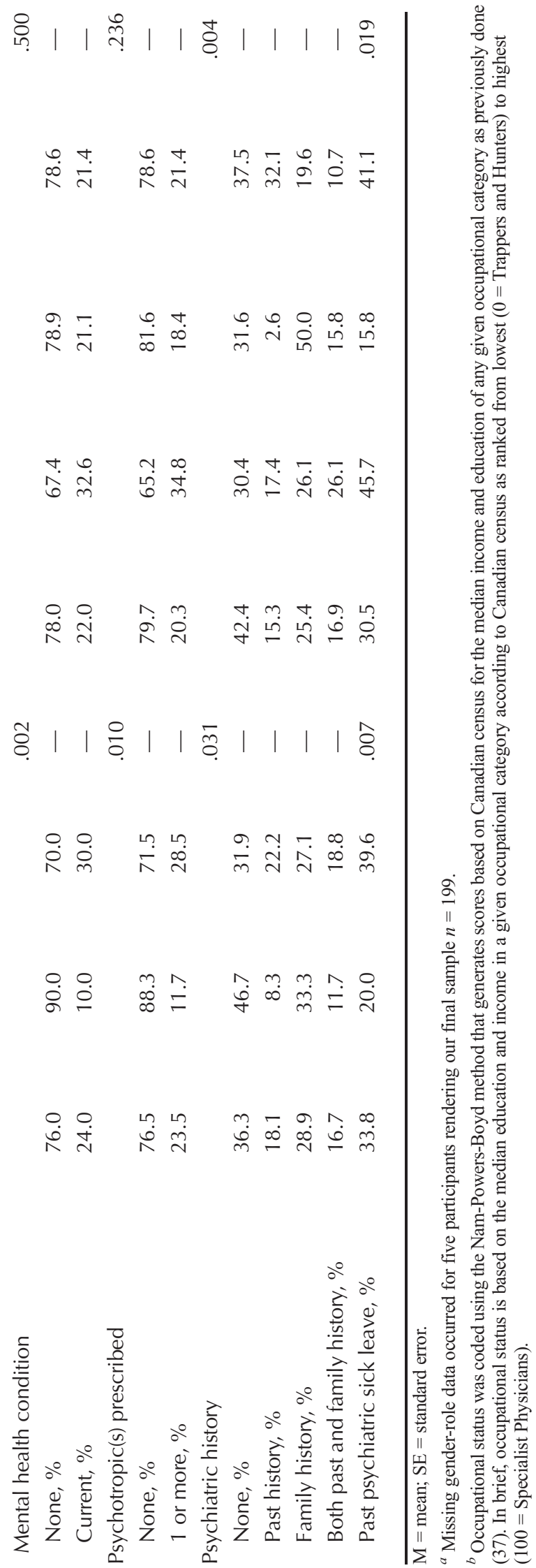

and 16 men), feminine-typed (32 women and 14 men), androgynous (26 women and $12 \mathrm{men}$ ), and undifferentiated (40 women and $16 \mathrm{men}$ ).

\section{Sexual Orientation}

The three-item Klein Sexual Orientation Scale (40) was used to measure sexual orientation along a continuum. This instrument uses a 7-point Likert scale to assess sexual attractions, sexual behavior, and sexual fantasies on a scale ranging from 1 (other sex only) to 7 (same sex only). Internal consistency was strong for our sample $(\alpha=.90)$. In addition, construct validity was confirmed as the Klein average was correlated $(r=0.76, p<.001)$ with the popular single-item Kinsey scale ranging from 0 (exclusively heterosexual) to 6 (exclusively homosexual). In light of positive skew and leptokurtic distribution due to predominately heterosexual proclivities, $3 \%$ of the sample identified as exclusively gay or lesbian. Notwithstanding, even incremental deviations from strictly heterosexual scoring are meaningful when considering sexual orientation along a continuum (41). Given our past findings linking sexual orientation to stress physiology and mental health $(30,31)$, all main analyses adjust for sexual orientation as a continuous variable.

\section{Self-Esteem}

The 10-item Rosenberg Self-Esteem Scale (42) represents a person's global self-worth using a 4-point Likert scale ranging from 1 (strongly disagree) to 4 (strongly agree) to statements about oneself (e.g., I feel that I have a number of good qualities). The instrument has adequate test-retest reliability $(r$ values $=0.82-0.88)$ and internal consistency $(\alpha=.83)$. Our sample responded reliably $(\alpha=.88)$.

\section{Well-Being}

The 14-item Mental Health Continuum (43) was used to assess emotional, psychological, and social well-being using a 6-point Likert scale ranging from 0 (never) to 5 (everyday). This instrument is internally consistent $(\alpha=.80)$ with test-retest reliability averages between 4 weeks, 3 months, and 9 months ranging respectively at $r=0.57, r=0.64$, and $r=0.71$. Internal consistency was high for the current sample $(\alpha=.93)$.

\section{Social Support}

Perceived social support was measured using the 20-item Perceived Social Support Scale (44). This scale assesses perceived social support using a Likert-scale ranging from 1 (strongly disagree) to 4 (strong agree) to statements regarding feelings and experiences via relationships with friends at one time or another. This instrument shows high test-retest reliability over a month $(r=0.83)$ and internal consistency $(\alpha=.90)$. A sum score is used and was similarly reliable for the present sample $(\alpha=.90)$.

\section{Depressive Symptoms}

The 21-item Beck Depression Inventory II (45) was administered to assess depressive symptoms using a 4-point Likert scale ranging from 0 to 3 in accord to statements (e.g., I feel sad) within the last 2 weeks. Original psychometrics revealed high test-retest reliability $(r=0.93)$ and internal consistency $(\alpha=.91)$. Using a total sum score, our sample's reliability was identical $(\alpha=.91)$.

\section{Chronic Stress}

The 30-item Trier Inventory for the Assessment of Chronic Stress (46) measured chronic stress on a 5-point Likert scale ranging from 0 (never) to 4 (very often) over the past month. Test-retest reliability $(r$ values $=0.60-0.91)$, internal consistency $(\alpha$ values $=.61-.93)$, and intercorrelations $(r$ values $=0.42-0.63)$ were acceptable for the following subscales: work overload, work discontent, overextended at work, performance pressure at work, worry propensity, social overload, social tension, lack of social recognition, performance pressure in social interactions, and social isolation. These subscales were aggregated into an index 
representing chronic stress that showed high internal consistency in our sample $(\alpha=.90)$. One-third of Canadians report chronic stress (47) that is moreover theoretically interlinked to AL. We therefore adjust for chronic stress in AL analysis to ensure that any effects of gender-role classification on AL are over and above those attributable to psychosocial factors at home and at work.

\section{Biomarkers}

\section{Allostatic Load}

AL was calculated using 20 biomarkers reported in Tables 2 and 3. Repeated measures of the stress hormone cortisol allowed us to assess diurnal variation and stress reactive variation that was summarized using timedependent formula and then incorporated into our AL indices. For diurnal cortisol, we calculated two values representing the diurnal cortisol awakening response (difference between +30 minutes after awakening and awakening) and diurnal cortisol bedtime based on the average for two nonconsecutive workdays reported in detail elsewhere $(36,48)$. For reactive cortisol, six measurements of cortisol collected throughout the Trier Social Stress Test (38) were transformed using the area under the curve with respect to ground (AUCg) formula derived from the trapezoid formula to summarize hypothalamic-pituitary-adrenal axis systemic output (49). Likewise, heart rate $A U C g$, systolic blood pressure $A U C \mathrm{~g}$, and diastolic blood pressure $A U C g$ were used based on four cardiovascular recordings obtained throughout the Trier Social Stress Test.

As part of a 12-hour fasting blood draw on their second visit, a licensed nurse extracted $44 \mathrm{ml}$ of blood from participants. The local hospital laboratory assayed serum dehydroepiandrosterone-sulphate, C-reactive protein, albumin, creatinine, glycosylated hemoglobin, total cholesterol, high-density lipoprotein, and triglycerides. Serum insulin and fibrinogen levels were shipped off and assayed at Maisonneauve-Rosemont Hospital (Montreal, Quebec, Canada). Isolated plasma was used to assay tumor necrosis factor $\alpha$ and interleukin- 6 at the Centre for Studies on Human Stress.

Two alternative AL formulations were applied to calculate a) an allinclusive AL index without regard for sex differences in biomarker distributions as is generally done in AL studies (16) and b) a sex-specific AL index with sex-specific cutoffs (19). In both cases, we used either one-tailed or two-tailed percentiles (50). Specifically, the 75th percentile was used for biomarkers in which high levels are dangerous, the 25th percentile was used for biomarkers in which low levels are dangerous, or both the 12.5th and 87.5th percentiles were used for biomarkers (e.g., cortisol) in which both hypoactive and hyperactive functioning is considered dangerous. Biomarkers attaining these critical cutoffs were ascribed a score of "1," whereas those in a healthy range were ascribed a score of " 0 ". In sum using 20 biomarkers, AL indices represent the number of dysregulated biomarkers for each individual. Any use of medication(s) was automatically added as " 1 " and none was scored as " 0 " to AL indices.

\section{Sex Hormones}

Sex hormones were used as covariates in main analyses of AL. Our rationale is that accounting for sex hormone variations in both sexes is the strongest way to account for biological sex-based modulation of stress physiology linked to $\mathrm{AL}(8,51)$. Although this is critical in stress studies on sex differences (36), few studies adjust accordingly for sex hormone functioning (36).

Two saliva samples were used to assess diurnal testosterone, estradiol, and progesterone concentrations during work and/or home collection in adjunct to diurnal cortisol sampling (36). Reliability analyses revealed acceptable intercorrelations between the two repeated measures of diurnal testosterone (women: $r=0.62, p<.001$; men: $r=0.60, p<.001$ ), estradiol (women: $r=0.58, p<.001$; men: $r=0.49, p<.001$ ), and progesterone (women: $r=0.83, p<.001$; men: $r=0.60, p<.001$ ). No associations were detected vis-à-vis seasonal variation or days since last menstruation among women of reproductive age, even when stratified according to reproductive status. This emphasizes the importance of accounting for objective biometrics of reproductive functioning instead of subjective reports when assessing sex differences in stress physiology.

\section{Statistical Analysis}

Analyses were run using the Statistical Package for the Social Sciences Macintosh Version 22. Power analyses were computed using G*Power 3.1. Missing data for gender roles $(n=5)$ and AL biomarkers $(n=25)$ are reflected by varying degrees of freedom throughout our statistical analyses.

Preliminary analyses assessed psychosocial gender factors, demographics, interpersonal, health behaviors, and physical/mental health domains (Table 1) using analysis of variance or $\chi^{2}$ when appropriate as a function of sex and of gender roles in turn. A correlation matrix of sex/gender factors and outcomes used Pearson correlations for descriptive purposes (Table 4).

Main analyses used analysis of covariance (ANCOVA) for mental health and $\mathrm{AL}$ while adjusting for covariates specified in respective subsections. Significance was set at $\alpha=.05$; however, we report trends at $p<.10$ in the interest of transparency. Post hoc analyses were scrutinized using Tukey analyses with 95\% confidence intervals (CIs). Effect sizes are reported throughout and can be interpreted according to the following conventions: $\eta_{\mathrm{P}}^{2} \cong 0.01$ represents a small effect, $\eta_{\mathrm{P}}^{2} \cong 0.06$ a medium effect, and $\eta_{\mathrm{P}}^{2} \cong 0.14$ constitutes a large effect.

Inspired by the method developed by Pelletier et al. (34) to index gender, we used principal axis factoring and logistic regression. Specifically in sequence, a) we identified variables related to psychosocial gender in preliminary analyses of sex differences in sample characteristics (Table 1), b) factor loaded these variables onto components, c) used these components to predict the probability of being a man or a woman, and d) finally used this probability to represent the composite gender index that we correlated with mental health and AL.

\section{RESULTS}

\section{Sample Characteristics}

Table 1 reports the sample's descriptive statistics. Men had higher Bem masculinity gender-role scores $(p<.001)$ than did women who in turn had higher Bem femininity genderrole scores $(p<.001)$. Sex and gender roles were also related to sexual orientation in our sample: men showed more nonheterosexual proclivities as evidenced by higher Klein sexual attraction $(p=.004)$, higher Kinsey scale scores $(p=.008)$, and a trend toward higher Klein sexual orientation averages $(p=.092)$ than did women. Despite no group differences according to gender-role classification ( $p$ values $>$.035), feminine gender roles were negatively associated with the Klein sexual orientation scale $(r=-0.16, p=.027)$ and Kinsey scale $(r=-0.14, p=.050)$; however, no associations were found for masculine gender roles ( $r$ values $>0.10$ ).

Preliminary analyses of group differences according to sex revealed that women were more likely than men to have a diagnosed mental health condition $(p=.002)$, psychotropic use $(p=.010)$, past psychiatric sick leave $(p=.031)$, and a trend toward higher occupational status $(p=.060)$. By contrast, men were more likely than women to use illicit drugs $(p=.001)$, while showing trends for consuming more alcohol $(p=.061)$ and worked more hours $(p=.093)$. 


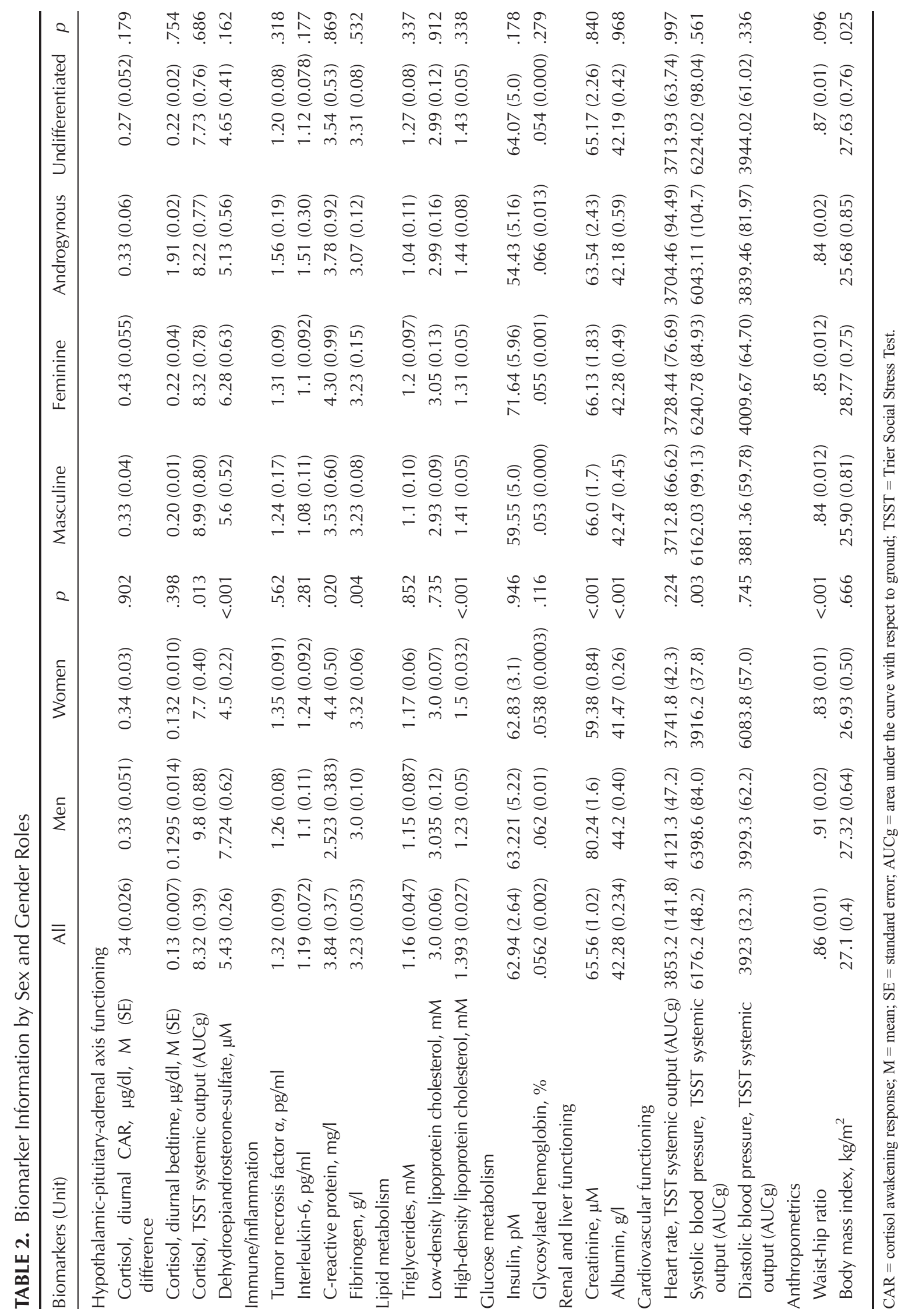


TABLE 3. Biomarker Information Used to Calculate "All-Inclusive" and "Sex-Specific" Allostatic Load Indices

\begin{tabular}{|c|c|}
\hline Biomarkers (Unit) & "All-Inclusive" and "Sex-Specific" Allostatic Load Cutoff(s) \\
\hline \multicolumn{2}{|l|}{ Hypothalamic-pituitary-adrenal axis functioning } \\
\hline Cortisol, diurnal CAR, $\mu \mathrm{g} / \mathrm{dl}, \mathrm{M}$ (SE) difference & $\begin{array}{c}\text { All: }<-0.0195 \text { or }>0.72 ; \text { 우: }<-0.02 \text { or }>0.71 ; \\
\text { o' }:<-0.0154 \text { or }>0.776\end{array}$ \\
\hline Cortisol, diurnal bedtime, $\mu \mathrm{g} / \mathrm{dl}, \mathrm{M}$ (SE) & $\begin{array}{l}\text { All: }<0.047 \text { or }>0.233 ; \text { 우: }<0.05 \text { or }>0.24 \\
\text { o }^{7}:<0.042 \text { or }>0.30\end{array}$ \\
\hline Cortisol, TSST systemic output (AUCg) & $\begin{array}{l}\text { All: }<3.85 \text { or }>13.83 ; \text { 우: }<3.6 \text { or }>12.6 \text {; } \\
\text { or: }:<4.513 \text { or }>16.86\end{array}$ \\
\hline Dehydroepiandrosterone-sulphate, $\mu \mathrm{M}$ & All: $<2.9$ 우: $<3.9 ;$ ○’: $<2.6$ \\
\hline \multicolumn{2}{|l|}{ Immune/inflammation } \\
\hline Tumor necrosis factor $\alpha, \mathrm{pg} / \mathrm{ml}$ & 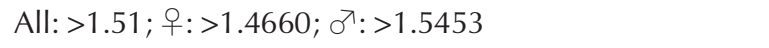 \\
\hline Interleukin-6, pg/ml & All: >1.435; 우: $1.4818 ;$ ㄱ: 1.2645 \\
\hline C-reactive protein, $\mathrm{mg} / \mathrm{l}$ & All: $>4.35 ;$ 우: $>5.1 ; \sigma^{\urcorner}:>3.7$ \\
\hline Fibrinogen, $\mathrm{g} / \mathrm{l}$ & All: $>3.73$; 우: $>3.77$; o': $>3.42$ \\
\hline \multicolumn{2}{|l|}{ Lipid metabolism } \\
\hline Triglycerides, mM & All: $>1.48$ 우: $>1.505 ; \sigma^{7}:>1.46$ \\
\hline Low-density lipoprotein cholesterol, mM & All: $>3.52$; 우: $>3.5325 ;$ 구: $>3.46$ \\
\hline High-density lipoprotein cholesterol, mM & All: <1.11; 우: <1.1975; ठํ:<1.0 \\
\hline \multicolumn{2}{|l|}{ Glucose metabolism } \\
\hline Insulin, $\mathrm{pM}$ & All: $>79.45$ 우: $>79.2 ; \sigma^{7}:>83.0$ \\
\hline Glycosylated hemoglobin, \% & All: $>0.055$; 오: $>0.055 ;$ ○’: >0.055 \\
\hline \multicolumn{2}{|l|}{ Renal and liver functioning } \\
\hline Creatinine, $\mu \mathrm{M}$ & 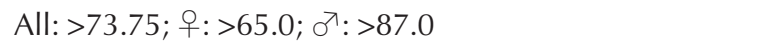 \\
\hline Albumin, g/l & All: $<40.00$; 우: $<40.0$; o': $<42.0$ \\
\hline \multicolumn{2}{|l|}{ Cardiovascular functioning } \\
\hline Heart rate, TSST systemic output (AUCg) & $\begin{array}{l}\text { All: }<3147.5 \text { or }>4402.5 ; \text { 우: }<3190.625 \text { or }>4340.625 \\
\text { o' }:<3075 \text { or }>4492.5\end{array}$ \\
\hline $\begin{array}{l}\text { Systolic blood pressure, TSST systemic } \\
\text { output (AUCg) }\end{array}$ & $\begin{array}{l}\text { All: }<5466.3 \text { or }>6962.5 ; \text { 우: }<5446.875 \text { or }>6800 \\
\text { oㄱ: }<5700 \text { or }>7140\end{array}$ \\
\hline $\begin{array}{l}\text { Diastolic blood pressure, } \\
\text { TSST systemic output (AUCg) }\end{array}$ & $\begin{array}{l}\text { All: }<3397.5 \text { or } 4461.25 ; \text { 우: }<3415 \\
\quad \text { or }>4412.5 ; \text { 구: }<3342.5 \text { or }>4562.5\end{array}$ \\
\hline \multicolumn{2}{|l|}{ Anthropometrics } \\
\hline Waist-hip ratio & All: $>91 ;$ 우: >0.8815; ত’: >0.964 \\
\hline Body mass index, $\mathrm{kg} / \mathrm{m}^{2}$ & All: $>30.34$; 우: $>30.197$; ס: $>30.6185$ \\
\hline
\end{tabular}

$\mathrm{CAR}=$ cortisol awakening response; $\mathrm{M}=$ mean; $\mathrm{SE}=$ standard error; $q=$ women; $\hat{\sigma}=$ men; $\mathrm{AUCg}=$ area under the curve with respect to ground; TSST $=$ Trier Social Stress Test

Preliminary analyses of group differences according to gender roles revealed a trend for years of education $(p=.064)$ and significance for number of children $(p=.017)$ that differed between groups. Post hoc analyses revealed that undifferentiated individuals had less education than did masculine individuals $(p=.044)$ and less children than did feminine individuals $(p=.041)$, while trending toward fewer children than androgynous individuals $(p=.076)$. In addition, undifferentiated individuals were most likely to have a psychiatric history, whereas androgynous individuals were most likely to have a family psychiatric history $\left(\chi^{2}(9)=24.21, p=.004\right)$. Conversely, androgynous individuals were least likely to have past sick leave themselves $\left(\chi^{2}(3)=9.94, p=.019\right)$. Main analyses therefore adjusted for mental health condition that correlated with psychotropic use $(r=0.91, p<.001)$ and psychiatric history $(r=0.568, p<.001)$.

\section{Sex and Gender Roles in Relation to Mental Health}

Mental health was assessed using two-way (sex by gender roles) ANCOVAs adjusted for mental health condition 


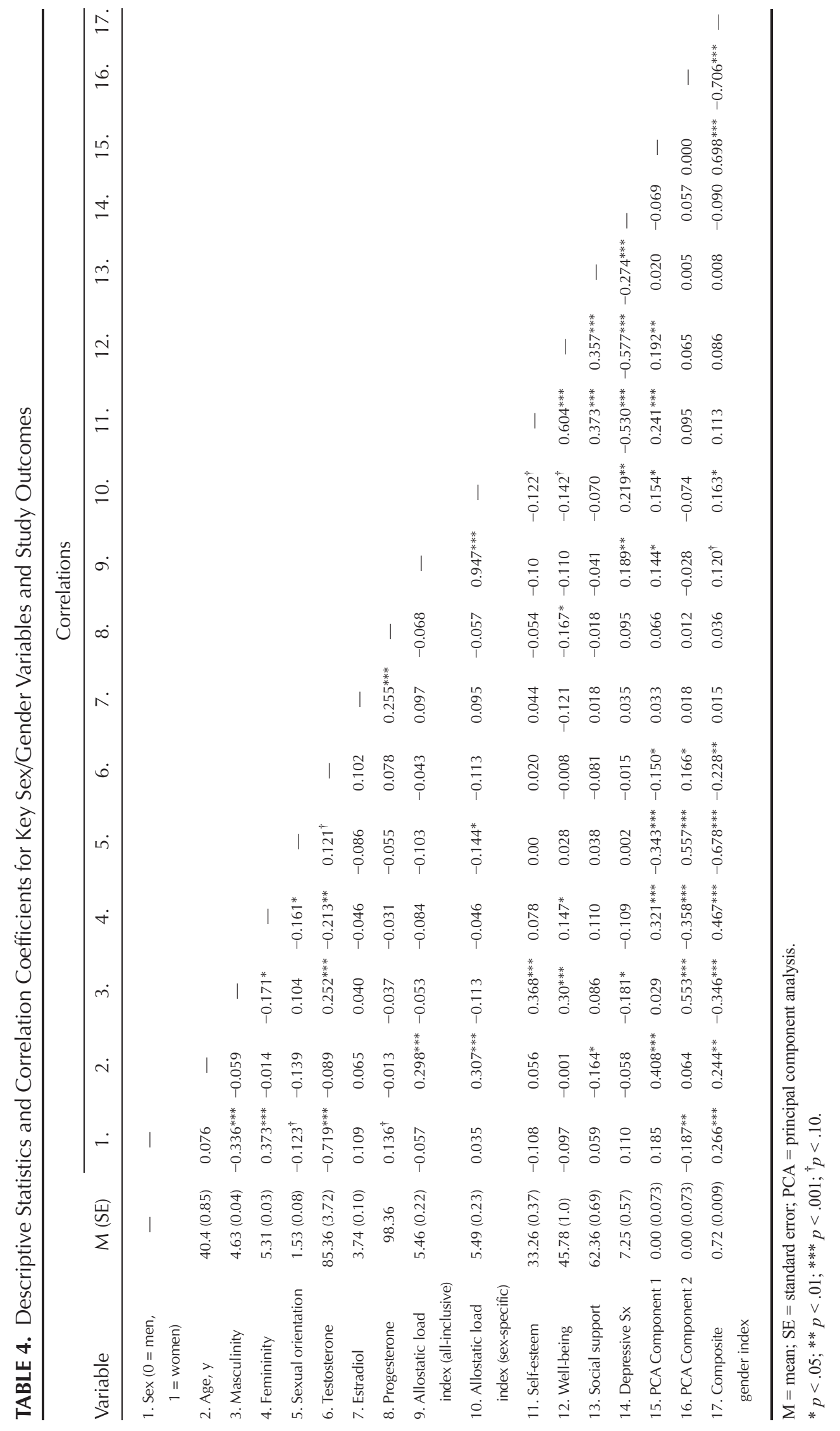


and sexual orientation. Sex was not related to self-esteem $\left(p=.172, \eta_{\mathrm{P}}^{2}=0.011\right)$, well-being $\left(p=.300, \eta_{\mathrm{P}}^{2}=0.006\right)$, social support $\left(p=.393, \eta_{\mathrm{P}}^{2}=0.004\right)$, or depressive symptoms $\left(p=.223, \eta_{\mathrm{P}}^{2}=0.009\right)$. By contrast, gender roles were significantly related to self-esteem $(F(3,174)=10.4, p<.001$, $\left.\eta_{\mathrm{P}}^{2}=0.152\right)$, well-being $\left(F(3,178)=6.5, p<.001, \eta_{\mathrm{P}}^{2}=0.099\right)$, and depressive symptoms $(F(3,174)=3.0, p=.033$, $\left.\eta_{\mathrm{P}}^{2}=0.049\right)$, but only trending for social support $(p=.076$, $\left.\eta_{\mathrm{P}}^{2}=0.038\right)$.

Figure 1 presents mental health as a function of gender roles irrespective of sex. Tukey post hoc analyses revealed that androgyny was related to higher self-esteem in contrast to undifferentiated ( $p<.001, \mathrm{CI}=3.38-8.52)$, femininetyped $(p=.010, \mathrm{CI}=0.52-5.41)$, and trending for masculine-typed ( $p=.056, \mathrm{CI}=-0.042$ to 4.92 ) individuals. In addition, masculine-typed $(p=.002, \mathrm{CI}=-6.04$ to -0.98$)$ and feminine-typed $(p=.012, \mathrm{CI}=-5.48$ to -0.49 ) individuals had higher self-esteem than did undifferentiated individuals. For well-being, androgynous individuals $(p<.001, \mathrm{CI}=-19.19$ to -5.08$)$, masculine-typed ( $p=.011, \mathrm{CI}=-15.47$ to -1.44$)$, and feminine-typed $(p=.020, \mathrm{CI}=-14.75$ to -0.91$)$ scored higher than did undifferentiated individuals. Finally, androgyny related to lower depressive symptoms ( $p=.047, \mathrm{CI}=0.044-$ 8.4 ) than did undifferentiated individuals, whereas the reverse trend was observed for social support $(p=.077$, $\mathrm{CI}=-0.35$ to 9.86 ). Although descriptive, the reader will note that depressive symptoms were positively correlated with AL reported in the following section (Table 4). Post hoc power analysis using obtained parameters yielded an achieved power $(1-\beta)$ of 0.97 .

\section{Sex and Gender Roles in Relation to AL}

AL was assessed using two formulations: a) all-inclusive cutoffs based on the entire sample's biomarker distributions and b) sex-specific cutoffs based on biomarker distributions for each sex separately. In both cases, identical two-way (sex by gender roles) ANCOVAs controlled for age, sex hormones (basal testosterone, estradiol progesterone), sexual orientation, chronic stress, and mental health condition.

First, using an all-inclusive AL index (Fig. 2A), a significant main effect for sex revealed that men had higher AL than did women $\left(F(1,164)=4.1, p=.044, \eta_{\mathrm{P}}^{2}=0.025\right)$ in addition to a covariation effect for age $(F(1,164)=16.9$, $\left.p<.001, \eta_{\mathrm{P}}^{2}=0.093\right)$. Exploring individual biomarkers revealed that half the biomarkers differed between the

Masculine $\square$ Feminine Androgynous $\square$ Undifferentiated

A

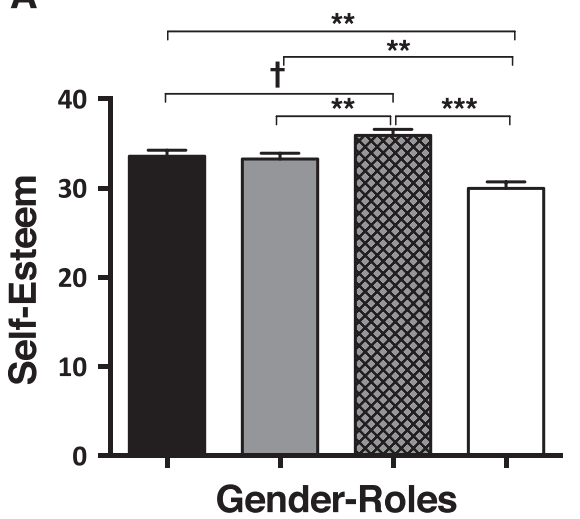

C

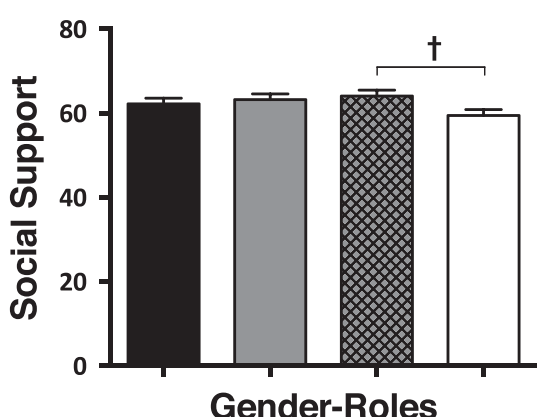

B

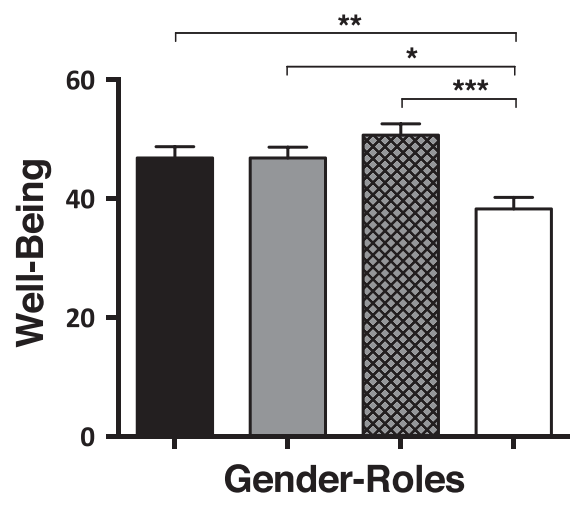

D

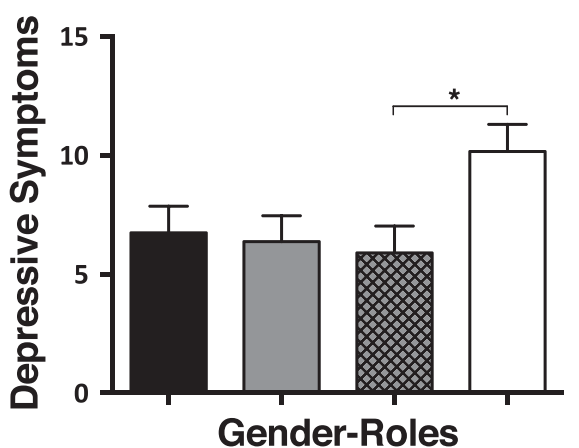

FIGURE 1. Estimated means $( \pm \mathrm{SE})$ for mental health outcomes as a function of gender roles while adjusting for sexual orientation and mental health condition. $\mathrm{SE}=$ standard error. $* p<.050 ; * * p<.010 ; * * * p<.001 ;{ }^{\dagger} p<.10$. 
A

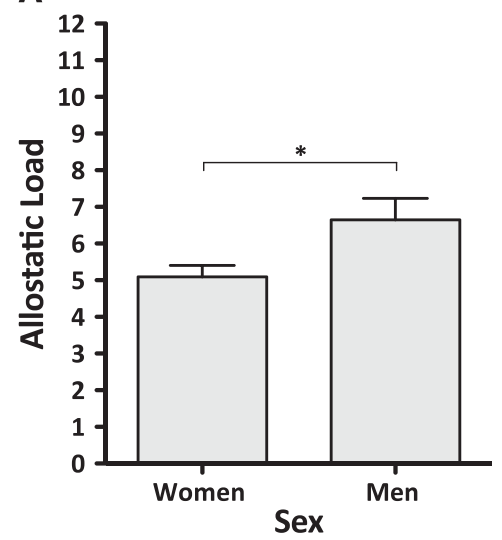

B

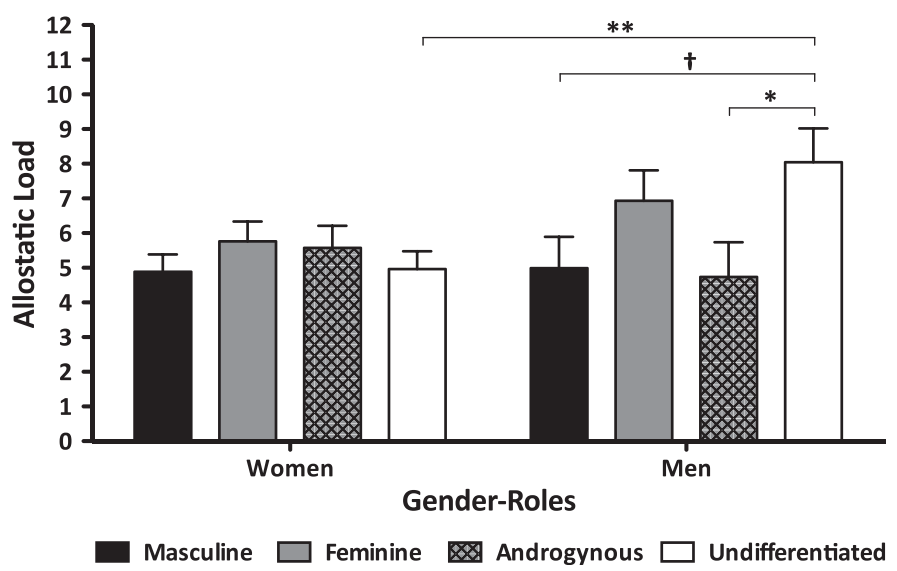

FIGURE 2. Estimated means ( \pm SE) for "all-inclusive" allostatic load as a function of sex (A) and "sex-specific" allostatic load as function of sex and gender roles (B) while adjusting for age, sex hormones (testosterone, estradiol, progesterone), sexual orientation, chronic stress, and mental health condition. $\mathrm{SE}=$ standard error. ${ }^{* *} p<.010 ; p<.050 ;{ }^{\dagger} p<.10$.

sexes (Table 2): compared with women, men had higher cortisol $(p=.013)$, dehydroepiandrosterone-sulphate $(p<.001)$, creatinine $(p<.001)$, albumin $(p<.001)$, systolic blood pressure $(p=.003)$, and waist-to-hip ratios $(p<.001)$ as well as lower C-reactive protein $(p=.020)$, fibrinogen $(p=.004)$, and high-density lipoprotein cholesterol $(p<.001)$.

Second, using the sex-specific AL index (Fig. 2B), we found a significant sex by gender role interaction effect $\left(F(3,164)=2.8, p=.043, \eta_{\mathrm{P}}^{2}=0.048\right)$, a main effect for gender roles $\left(F(3,164)=2.8, p=.040, \eta_{\mathrm{P}}^{2}=0.049\right)$, and a covariation effect for age $(F(1,164)=17.8, p<.001$, $\left.\eta_{\mathrm{P}}^{2}=0.098\right)$. Sex-specific reanalyses and Tukey post hoc comparisons revealed that undifferentiated men had higher AL than did androgynous men $(p=.015, \mathrm{CI}=0.56-6.78)$ and trending compared with masculine men $(p=.066$, $\mathrm{CI}=-0.13$ to 5.63 ). Splitting analysis by gender roles revealed that undifferentiated men had higher AL than did undifferentiated women $(F(1,39)=10.3, p=.003$, $\eta_{\mathrm{P}}^{2}=0.210$ ). For the main effect of gender roles, femininetyped had higher AL than did masculine-typed individuals; however, this did not approach statistical significance in post hoc analysis. The only biomarker that differed according to sex by gender roles was higher interleukin- 6 among women than men $(p=.014)$. In addition, androgynous women had higher concentrations than did masculine $(p=.011, \mathrm{CI}=0.15-1.53)$, undifferentiated $(p=.039$, $\mathrm{CI}=-1.44$ to -0.03 ), and trending in comparison to feminine ( $p=.082, \mathrm{CI}=-0.06$ to 1.41$)$ women. Post hoc power analysis using obtained parameters yielded an achieved power $(1-\beta)$ of 0.92 .

\section{Gender Index Constructed Using PCA and Logistic Regression}

Following an approach developed by Pelletier et al. (34), we used a PCA and logistic regression to generate a continuous gender index that we assessed in association to mental health and AL. Guided by preliminary analyses (Table 1), seven variables showing the most pronounced sex differences were selected based on their correspondence to psychosocial gender: a) Bem masculine gender roles, b) Bem feminine gender roles, c) Klein sexual attractions, d) occupational status, e) work hours per week, f) civil status, and g) number of children.

Table 5 provides the factor loadings for the PCA. Two components attained eigenvalues greater than 1 (eigenvalues of 1.6 and 1.3 cumulatively representing $41.5 \%$ of the explained variance) that were retained for varimax rotation. In accordance with convention, variables with a factor load of 0.40 and above were considered significant. First, Component 1 was positively associated with feminine gender roles, occupational status, being in a relationship, and number of children. Second, Component 2 was positively associated with masculine

TABLE 5. Gender-Related Component Factor Loadings Generated by Principal Component Analysis

\begin{tabular}{lcc}
\hline & Component 1 & Component 2 \\
\hline Masculine gender roles & .100 & $.592^{a}$ \\
Feminine gender roles & $.460^{a}$ & -.280 \\
Sexual attractions & -.367 & $.584^{a}$ \\
Occupational status & $.450^{a}$ & .289 \\
Work hours per week $^{a}$ & .141 & $.678^{a}$ \\
Civil status $^{b}$ & $.673^{a}$ & .093 \\
No. children & $.744^{a}$ & .026 \\
\hline
\end{tabular}

${ }^{a}$ Refers to variables that significantly load onto a component according to a cutoff $\geq .40$.

${ }^{b}$ Civil status was binary coded as 0 (single/separated/divorced) or 1 (relationship/common-law/married). 
gender roles, nonheterosexual attractions, and work hours per week. The two PCA components were calculated for every individual and used in a logistic regression predicting sex to create a composite gender index.

A binary logistic regression with the two PCA components entered as predictors of one's probability of being a man (0) or a woman (1) was significant $\left(\chi^{2}(2)=12.7\right.$, $p=.002$, Cox \& Snell $R^{2}=0.07$; Nagelkerke $R^{2}=0.09$ ). The probability of being a woman was positively associated with PCA Component $1(\beta=0.42, \mathrm{SE}=0.17, p=.015$, $\mathrm{OR}=1.52$ ) and negatively associated with PCA Component $2(\beta=-0.43, \mathrm{SE}=0.18, p=.018, \mathrm{OR}=0.66)$. This probability score generated by the regression is therefore the composite gender index representing the likelihood of one's sex as a man (more negative scores) or a woman (more positive scores) as initially predicted by the PCA components based on seven psychosocial gender-related factors.

Table 4 reveals that our composite gender index is correlated with key sex/gender variables. Despite no significant associations with mental health or the all-inclusive AL index, the gender index was positively correlated with the sex-specific AL index $(r=0.16, p=.025)$. To ensure that this association was independent of sex, partial correlations controlling for sex confirmed that the gender index was significantly correlated only with the sex-specific AL index $(r=0.16, p=.029)$ and as a trend with the all-inclusive $\mathrm{AL}$ index $(r=0.14, p=.053)$.

\section{DISCUSSION}

The goal of this study was to apply a sex by gender-based analysis of mental health and AL among healthy working adults recruited from a psychiatric hospital. To reiterate, Bem (11-13) postulated that androgynous individuals are psychologically adaptive because they aptly alternate between masculine and feminine gender roles. By contrast, undifferentiated individuals show low propensities for these gender roles and are thought to be at greater risk for psychopathology due to an inability to conform to societal expectations (13). Our hypotheses partially support Bem's theory in that androgyny seems to be biologically adaptive only among men while being psychologically adaptive for both sexes. In addition, a composite gender index representing a greater probability of multidimensional "femininity" was associated with AL based on sex-specific biomarker cutoffs independent of sex. Whether gender is measured categorically or continuously, our results suggest that a gendered lens allows us to understand stress-related disease trajectories that differ between the sexes.

Our sex by gender roles interaction for AL provides powerful evidence for Bem's proposal (11-13) that androgyny is advantageous in comparison to undifferentiation. But why would androgyny be protective against $\mathrm{AL}$ in men but not women? It is possible that high appropriation of both masculine and feminine gender roles is not as beneficial for women as it is for men. This androgynous combination is not new to modern women who have needed to appropriate masculine gender roles to break the "glass ceiling" of workplaces worldwide. Indeed, women have increased their participation in the workforce by $126 \%$ over the last 30 years (52) and represent $42 \%$ of the entire global labor force $(1,53,54)$. However, women around the world suffer more from competitive socioeconomic pressures, job insecurity, limited opportunities, and inadequate social benefits such as insurance and sick leave (5).

Pioneering research from the 1980s onward by Frankenhaeuser and Lundberg revealed that Scandinavian women in nontraditional or "masculine" occupations (e.g., managerial versus clerical) reported more distress, hostility, inability to recover after work, physical complaints when older, and manifested pathophysiological functioning $(55,56)$. The appropriation of multiple gender roles among working women has clearly not been matched by appropriate social equity. In general, women still retain more "feminine" roles and responsibilities than the average man in both work and home life $(1,34,57,58)$. This may explain why the AL burden is heaviest for feminine and androgynous women, but does not seem so for men. Indeed, masculine gender roles were associated with marginally lower AL than feminine gender roles. This is inconsistent with our past finding linking greater masculinity relative to femininity and elevated $A L$ in a much smaller sample of varied workers (29). Undifferentiated gender identity also seems here to be worst among men than women for AL. Future studies assessing factors inside and outside the workplace are warranted to help tease apart these mixed gender effects. In particular, age cohort effects and cross-cultural contrasts should be explored more broadly.

Methodologically, different AL formulations may capture distinct sex- versus gender-based effects. In our study, men had higher AL than women when using the traditional all-inclusive formulation. These sex differences were driven by nine biomarkers, suggesting that using this approach is most appropriate when endeavoring to understand biological sex differences. This was not the case when using the less common sex-specific formulation that instead captured the influence of sociocultural gender-role diversity. These alternative AL indices are not trivial because they could be helpful in nuancing main effects or interactions among gender-based factors (e.g., social networks, family responsibilities) versus biological factors like sex or age. Indeed, this distinction between all-inclusive versus sex-specific AL formulations should be considered in future studies aimed at respectively demarcating between-sex differences or within-sex diversity in AL and stress-related disease pathways.

Beyond our objectives focusing on Bem's gender schema theory, we expand upon recent endeavors to 
quantify psychosocial gender. Using a composite gender index constructed using a method developed by Pelletier et al. (34), we found that a greater propensity toward femininity was positively associated to the sex-specific AL index. This gender index was constructed using first our PCA resulting in the reduced seven gendered factors into two components: a) Component 1 derived from feminine gender roles, occupational status, civil status, and number of children and b) Component 2 derived from masculine gender roles, nonheterosexual attractions, and work hours. Our finding therefore compliments the work of Pelletier et al., (34) who showed in a large cohort that a feminine gender index based on seven components corresponded with a greater propensity toward premature cardiovascular disease and recurring complications for 1 year (59). Similarly using the same cohort, those with more feminine gender show poorer access to care than do men and women with more masculine gender-related characteristics (60). Although our result is of weak statistical magnitude, using innovate methods to similarly construct gender indices provides a unique way to delineate psychosocial contexts related to but still distinct from one's sex that are related to AL (61).

Previous research has shown that gender roles are predictive of health outcomes, but not necessarily independently from one's biological sex (62-64). Our findings carefully adjusted for sex hormones and sexual orientation among other covariates, which provides insights specifically due to sex and gender. This is critical when endeavoring to understand health problems, especially when we consider that objective and subjective measures of stress may manifest themselves differently according to sex/ gender. Indeed, women self-report more perceived stressors, psychosocial distress, and physical complaints than do men (65-67). By contrast, men are generally more biologically stress responsive at younger ages $(68-71)$. It is possible that changing gender roles might also influence men in ways that have yet to be studied fully using sexand gender-based approaches. For example, a Swedish study found that paternity leave - " a departure from traditional masculinity" - was associated with decreased mortality among fathers (33). Gendered coping strategies interact with numerous intersecting factors to influence how individuals deal with major stressful events in their lives that should be explored.

Independent of sex, androgynous individuals selfreported higher self-esteem, better well-being, and less depressive symptoms than did undifferentiated individuals. In addition, undifferentiated individuals had lower selfesteem and well-being than did masculine-typed and feminine-typed individuals. In terms of descriptive characteristics, undifferentiated individuals were less educated than masculine gender types, had fewer children than did feminine gender types, and were the most likely to have had a past psychiatric episode. By contrast, androgynous individuals were more likely to have a family psychiatric history, yet less likely to have had past sick leave. Taken together, these profiles concord with a large body of theoretical and empirical literature on the advantages of androgyny and the disadvantages of undifferentiation (10-13,72). They do, however, beg the following question: who are undifferentiated individuals and what can be done to help them? Although beyond the scope of the current study, answering these questions represents vital empirical and clinical future directions.

Critically, interventions attempting to reverse deleterious pathways may be complicated by the fact that sex is so often totally disregarded in clinical research (73). For example, a critique of 38 Cochrane systemic reviews on cardiovascular disease identified that sex and gender were rarely considered despite mounting evidence that sex influences heart health (74). Given that Cochrane guidelines are considered to use rigorous standards for inclusion, this is particularly troublesome. More broadly in preclinical and clinical research (e.g., randomized controlled trials), the disaggregation of findings on the basis of sex is fundamental $(33,75,76)$. Disregard for sex/gender is especially problematic for the prevalence of numerous stress-related diseases that we argue is crucial for the advancement of the AL model. Measuring sex as a binary classification is clearly not sufficient when attempting to understand differences between men, women, and gender diverse individuals.

\section{Limitations}

Several considerations limit our findings. Despite a respectable sample size, men were underrepresented. A systematic review of workplace AL studies reports that men characterize $46 \%$ of participants that are predominantly European professionals working in different industries (77). Despite fewer men, our study is unique in assessing diverse professionals of both sexes working in the same hospital environment, but which also constrains generalizability. Relatedly, because the focus of this study was on the role of sex- and gender-based factors, the role of work and home life was not scrutinized beyond inclusion within our gender index. Our sample was moreover heterogeneous and individuals reported varying degrees of distress and mental health. Although all participants were healthy enough to be working, it is difficult to compare our study to those using stricter exclusion criteria or who study samples suffering from specific diseases.

The Bem Sex Role Inventory has psychometric issues (72) and using median splits are controversial. The internal consistency of the femininity subscale was also significantly weaker than that of the masculinity subscale, suggesting that masculine gender roles are preferentially selfendorsed among this sample of psychiatric hospital workers. Most importantly, gender roles have changed considerably since the mid-1970s and may render this 
measure of gender roles outdated and in need of an update. Nevertheless, men did score higher on masculinity and women higher on femininity, suggesting that Bem's gendered stereotypes remain applicable today. Although descriptive (Table 4), it is also noteworthy that testosterone concentrations were positively correlated with masculine gender roles and negatively correlated with feminine gender roles, providing unique triangulation of methods that should be explored further. Correcting for multiple comparisons would, however, render these results nonsignificant, emphasizing the preliminary nature of these correlations.

At a theoretical level, our findings force us to conceptually move beyond bipolar views not only of men and women but also of masculinity and femininity. In developing her theory that androgynous individuals are more adaptively "flexible," Bem (11) proposed that masculine and feminine gender roles are independent entities and therefore not binary. However, when interpreting gender roles along continuums, it is easy to resort to simplifications that can make masculine and feminine gender roles seem like oppositional constructs when they are two independent dimensions that are in fact context-specific. Hammarström (78) has noted that gender-role theories assume an opposite coexistence (e.g., "active" versus "passive," men are from Mars and women are from Venus). Researchers must be cautious with such dichotomizations (79). In accordance, we did not find marked differences when contrasting masculine and feminine individuals, but instead when comparing androgynous and undifferentiated individuals or when assessing gender multidimensionally. Although our results provide psychobiological support for Bem's hypothesis, continuous gender indices provided an additional layer of complexity transcending outdated definitions of gender roles. This is consistent with recent approaches that emphasize sex/gender "mosaics" along continuums rather than categories (80).

\section{CONCLUSIONS}

To the best of our knowledge, this is the first study to comprehensively assess the influence of biological sex and sociocultural gender roles in relation to AL and mental health. We show that androgyny, especially among men, seems to be psychobiologically adaptive. In addition using various gendered factors, we showed that a tendency toward greater femininity was associated with elevated AL. Our results contribute to a sequestered literature where biomedical perspectives of sex and psychosocial perspectives of gender are rarely studied together (32). Applying a sex- and genderbased analysis recognizes this plurality of individuality and can be viewed as an iterative process that evolves by refining research methodologies that promote equity in science, policy, and practice $(28,81)$. At a methodological level, our AL findings show that different formulations may capture sex effects (all-inclusive) versus gender effects (sex-specific).
In conclusion, our findings suggest that stress researchers should abstain from studying sex as a dichotomy and focus further on gender diversity when endeavoring to understand disease trajectories that are not always sex-specific.

We wish to thank our participants for their contributions. This project would not have been possible without the nurse services of Mimi Dumont, Soaud Lahlafi, Carole Feltrin, and Louise Normandeau. Thanks are also expressed to Helen Findlay for bioassay determination, Joanne Beausejour for administrative assistance, and Catherine Dion for communications support. Thanks to Christopher Cardoso and Bruce McEwen for their encouragements.

Source of Funding and Conflicts of Interest: This study was supported by the Canadian Institutes of Health Research (CIHR) Institute of Gender and Health (Grant No. 222055) awarded to S. J. Lupien (Principal Investigator), E. Kouassi, and A. Lesage. S. J. Lupien held a senior investigator chair on Gender and Mental Health from the CIHR Institute of Gender and Health (Grant No. GSC 91039). R. P. Juster held a doctoral scholarship from the CIHR Institute of Aging (Grant No. SIA 95402) and support from the Research Team on Work and Mental Health (ERTSM). The authors have no conflicts to report.

\section{REFERENCES}

1. WHO. Gender Equality, Work and Health: A Review of the Evidence. Geneva: World Health Organization; 2006.

2. Dedovic K, Wadiwalla M, Engert V, Pruessner JC. The role of sex and gender socialization in stress reactivity. Dev Psychol 2009;45:45-55.

3. Plotnikoff R. Women, Heart Disease and Stroke in Canada: Issues and Options. Ottawa: Heart and Stroke Foundation of Canada; 1997.

4. Pilote L, Dasgupta K, Guru V, Humphries KH, McGrath J, Norris C, Rabi D, Tremblay J, Alamian A, Barnett T, Cox J, Ghali WA, Grace S, Hamet P, Ho T, Kirkland S, Lambert M, Libersan D, O'Loughlin J, Paradis G, Petrovich M, Tagalakis V. A comprehensive view of sex-specific issues related to cardiovascular disease. CMAJ 2007;176:S1-44.

5. WHO. Gender, Health and Work. Department of Gender WaHaDoPotHE, editor. Geneva: World Health Organization; 2004

6. Fuhrer R, Stansfeld SA, Chemali J, Shipley MJ. Gender, social relations and mental health: prospective findings from an occupational cohort (Whitehall II study). Soc Sci Med 1999;48:77-87.

7. Annandale E, Hunt K. Masculinity, femininity and sex: an exploration of their relative contribution to explaining gender differences in health. Sociol Health Illness 1990;12:24-46.

8. Juster RP, Bizik G, Picard M, Arsenault-Lapierre G, Sindi S, Trepanier L, Marin MF, Wan N, Sekerovic Z, Lord C, Fiocco AJ, Plusquellec P, McEwen BS, Lupien SJ. A transdisciplinary perspective of chronic stress in relation to psychopathology throughout life span development. Dev Psychopathol 2011;23:725-76. 
9. Evans O, Steptoe A. The contribution of gender-role orientation, work factors and home stressors to psychological well-being and sickness absence in male- and femaledominated occupational groups. Soc Sci Med 2002;54: 481-92.

10. Knaak S. On the reconceptualizing of gender: implications for research design. Sociol Inq 2004:302-17.

11. Bem SL. The measurement of psychological androgyny. J Consult Clin Psychol 1974;42:155-62.

12. Bem SL. Gender schema theory: a cognitive account of sex typing. Psychol Rev 1981;88:354-64.

13. Bem SL. On the utility of alternative procedures for assessing psychological androgyny. J Consult Clin Psychol 1977; 45:196-205.

14. McEwen BS. Sex, stress and the hippocampus: allostasis, allostatic load and the aging process. Neurobiol Aging 2002; 23:921-39.

15. McEwen BS, Stellar E. Stress and the individual. Mechanisms leading to disease. Arch Intern Med 1993;153: 2093-101.

16. Seeman TE, Singer BH, Rowe JW, Horwitz RI, McEwen BS. Price of adaptation - allostatic load and its health consequences. MacArthur studies of successful aging. Arch Intern Med 1997;157:2259-68.

17. Juster RP, McEwen BS, Lupien SJ. Allostatic load biomarkers of chronic stress and impact on health and cognition. Neurosci Biobehav Rev 2010;35:2-16.

18. Beckie TM. A systematic review of allostatic load, health, and health disparities. Biol Res Nurs 2012;14:311-46.

19. Juster RP, Moskowitz DS, Lavoie J, D'Antono B. Sex-specific interaction effects of age, occupational status, and workplace stress on psychiatric symptoms and allostatic load among healthy Montreal workers. Stress 2013;16:616-29.

20. Goel N, Workman JL, Lee TT, Innala L, Viau V. Sex differences in the HPA axis. Compr Physiol 2014;4:1121-55.

21. Lupien SJ, Ouellet-Morin I, Hupbach A, Walker D, Tu MT, Buss C, Pruessner J, McEwen B. Beyond the stress concept: allostatic load - a developmental biological and cognitive perspective. In: Cicchetti D, ed. Handbook Series on Developmental Psychopathology. Hoboken, NJ: John Wiley \& Sons; 2006. 784-809.

22. Kubzansky LD, Kawachi I, Sparrow D. Socioeconomic status, hostility, and risk factor clustering in the Normative Aging Study: any help from the concept of allostatic load? Ann Behav Med 1999;21:330-8

23. Sun J, Wang S, Zhang JQ, Li W. Assessing the cumulative effects of stress: the association between job stress and allostatic load in a large sample of Chinese employees. Work Stress 2007;21:333-47.

24. Seeman T, Glei D, Goldman N, Weinstein M, Singer $\mathrm{B}$, Lin YH. Social relationships and allostatic load in Taiwanese elderly and near elderly. Soc Sci Med 2004; 59:2245-57.

25. Seeman TE, Singer BH, Ryff CD, Dienberg Love G, LevyStorms L. Social relationships, gender, and allostatic load across two age cohorts. Psychosom Med 2002;64:395-406.

26. Maselko J, Kubzansky L, Kawachi I, Seeman T, Berkman L. Religious service attendance and allostatic load among highfunctioning elderly. Psychosom Med 2007;69:464-72.

27. Lindfors P, Lundberg O, Lundberg U. Allostatic load and clinical risk as related to sense of coherence in middle-aged women. Psychosom Med 2006;68:801-7.

28. Clow BN, Dederson A, Haworth-Brockman M, Bernier J Rising to the challenge: sex- and gender-based analysis of health planning, policy and research in Canada. Halifax,
Nova Scotia: Atlantic Centre of Excellent for Women's Health; 2009.

29. Juster RP, Lupien S. A sex- and gender-based analysis of allostatic load and physical complaints. Gend Med 2012;9: $511-23$.

30. Juster RP, Hatzenbuehler ML, Mendrek A, Pfaus JG, Smith NG, Johnson PJ, Lefebvre-Louis JP, Raymond C, Marin MF, Sindi S, Lupien SJ, Pruessner JC. Sexual orientation modulates endocrine stress reactivity. Biol Psychiatry 2015; 77:668-76.

31. Juster RP, Smith NG, Ouellet É, Sindi S, Lupien SJ. Sexual orientation and disclosure in relation to psychiatric symptoms, diurnal cortisol, and allostatic load. Psychosom Med 2013;75: $103-16$.

32. Hammarström A, Annandale E. A conceptual muddle: an empirical analysis of the use of "sex" and "gender" in "genderspecific medicine" journals. PLoS One 2012;7:e34193.

33. Phillips SP. Measuring the health effects of gender. J Epidemiol Community Health 2008;62:368-71.

34. Pelletier R, Ditto B, Pilote L. A composite measure of gender and its association with risk factors in patients with premature acute coronary syndrome. Psychosom Med 2015; 77:517-26.

35. Lupien SJ, Ouelle-Morin I, Hupback A, Walker D, Tu MT, Buss C, Pruessner J, McEwen BS. Beyond the Stress Concept: Allostatic Load-A Developmental Biological and Cognitive Perspective. In: Cicchetti D, editor. Handbook Series on Developmental Psychopathology. Wisconsin: Wiley; 2006. 784-809.

36. Juster RP, Raymond C, Desrochers AB, Bourdon O, Durand N, Wan N, Pruessner JC, Lupien SJ. Sex hormones adjust "sex-specific" reactive and diurnal cortisol profiles. Psychoneuroendocrinology 2016;63:282-90.

37. Boyd M. A socioeconomic scale for Canada: measuring occupational status from the census. Can Rev Sociol 2008; 45:51-91.

38. Kirschbaum C, Pirke KM, Hellhammer DH. The 'Trier Social Stress Test' - a tool for investigating psychobiological stress responses in a laboratory setting. Neuropsychobiology 1993; 28:76-81.

39. Bem S. Bem Sex Role Inventory: Professional Manual. In: Press CP, editor. Palo Alto, CA: Consulting Psychologists Press; 1981.

40. Klein F, Sepekoff B, Wolf TJ. Sexual orientation: a multivariable dynamic process. In: Geller T, ed. Bisexuality: A Reader and Sourcebook. Ojai, CA: Times Change Press; 1990.

41. Savin-Williams RC, Vrangalova Z. Mostly heterosexual as a distinct sexual orientation group: a systematic review of the empirical evidence. Dev Rev 2013;33:55-88.

42. Rosenberg M. Society and the Adolescent Self-Image. Princeton, NJ: Princeton University Press; 1965.

43. Keyes CLM. The mental health continuum: from languishing to flourishing in life. J Health Soc Behav 2002;43:207-22.

44. Procidano ME, Heller K. Measures of perceived social support from friends and from family: three validation studies. Am J Community Psychol 1983;11:1-24.

45. Beck AT. Manual for the Beck Depression Inventory. San Antonio, TX: Psychological Corporation; 1996.

46. Schulz P. Entwicklung eines Fragebogens zur Erfassung von chronischem Stress und protektiven Faktoren. Trier Pscyh Berichte 1995;22:1-49.

47. Dewa CS, Lin E, Kooehoorn M, Goldner E. Association of chronic work stress, psychiatric disorders, and chronic physical conditions with disability among workers. Psychiatr Serv 2007;58:652-8. 
48. Juster RP, Preussner JC, Lupien SJ. Diurnal and stress reactive cortisol profiles are altered when adjusting for sex hormones. Psychoneuroendocrinology 2015;61:69.

49. Pruessner JC, Kirschbaum C, Meinlschmid G, Hellhammer $\mathrm{DH}$. Two formulas for computation of the area under the curve represent measures of total hormone concentration versus time-dependent change. Psychoneuroendocrinology 2003;28:916-31.

50. Seplaki CL, Goldman N, Glei D, Weinstein M. A comparative analysis of measurement approaches for physiological dysregulation in an older population. Exp Gerontol 2005; 40:438-49.

51. McEwen BS. Allostasis and allostatic load: implications for neuropsychopharmacology. Neuropsychopharmacology 2000; 22:108-24.

52. World-Bank. Engendered Development. New York: Oxford University Press; 2001.

53. WHO. Occupational Health, Ethically Correct, Economically Sound. Geneva: World Health Organization. 1999.

54. ILO. Yearbook. Geneva: Internation Labour Office; 2000.

55. Lundberg U, Frankenhaeuser M. Stress and workload of men and women in high-ranking positions. J Occup Health Psychol 1999;4:142-51.

56. Frankenhaeuser M. Stress and gender. Eur Rev 1996;4:313-27.

57. Lagerlof E. Global Gender Issues in Relation To Health And Industrial Work. Geneva: World Health Organization; 2005.

58. Lundberg U. Stress hormones in health and illness: the roles of work and gender. Psychoneuroendocrinology 2005;30:1017-21.

59. Pelletier R, Khan NA, Cox J, Daskalopoulou SS, Eisenberg MJ, Bacon SL, Lavoie KL, Daskupta K, Rabi D, Humphries KH, Norris CM, Thanassoulis G, Behlouli H, Pilote L, Investigators G-P. Sex versus gender-related characteristics: which predicts outcome after acute coronary syndrome in the young? J Am Coll Cardiol 2016;67:127-35.

60. Pelletier R, Humphries KH, Shimony A, Bacon SL, Lavoie KL, Rabi D, Karp I, Tsadok MA, Pilote L; GENESISPRAXY Investigators. Sex-related differences in access to care among patients with premature acute coronary syndrome. CMAJ 2014;186:497-504.

61. Juster RP, Seeman T, McEwen BS, Picard M, Mahar I, Mechawar N, Sindi S, Smith NG, Souza-Talarico J, Sarnyai Z, Lanoix D, Plusquellec P, Ouellet-Morin I, Lupien SJ. Social inequalities and the road to allostatic load: from vulnerability to resilience. In: Cicchetti D, ed. Developmental Psychopathology Handbook. 3rd ed. New York, NY: Cambridge Press. In press.

62. Williams PG, Wiebe DJ. Individual differences in selfassessed health: gender, neuroticism and physical symptom reports. Pers Individ Diff 2000;28:823-35.

63. Klonoff EA, Landrine H. Sex roles, occupational roles, and symptom-reporting: a test of competing hypotheses on sex differences. J Behav Med 1992;15:355-64.

64. van Wijk CM, Kolk AM. Psychometric evaluation of symptom perception related measures. Pers Individ Diff 1996:20.

65. van Wijk CM, Kolk AM. Sex differences in physical symptoms: the contribution of symptom perception theory. Soc Sci Med 1997:45:231-46.
66. Pennebaker JW. The Psychology of Physical Symptoms. New York: Springer-Verlag; 1982.

67. Verbrugge LM. Gender and health: an update on hypotheses and evidence. J Health Soc Behav 1985;26:156-82.

68. Kirschbaum C, Wüst S, Hellhammer DH. Consistent sex differences in cortisol responses to psychological stress. Psychosom Med 1992;54:648-57.

69. Kudielka BM, Buske-Kirschbaum A, Hellhammer DH, Kirschbaum C. HPA axis responses to laboratory psychosocial stress in healthy elderly adults, younger adults, and children: impact of age and gender. Psychoneuroendocrinology 2004;29:83-98

70. Kudielka BM, Hellhammer J, Hellhammer DH, Wolf OT, Pirke KM, Varadi E, Pilz J, Kirschbaum C. Sex differences in endocrine and psychological responses to psychosocial stress in healthy elderly subjects and the impact of a 2-week dehydroepiandrosterone treatment. J Clin Endocrinol Metab 1998;83:1756-61.

71. Kudielka BM, Hellhammer DH, Wüst S. Why do we respond so differently? Reviewing determinants of human salivary cortisol responses to challenge. Psychoneuroendocrinology 2009;34:2-18.

72. Hoffman RM, Borders D. Twenty-five years after the Bem Sex-Role Inventory: a reassessment and new issues regarding classification variability. Meas Eval Counsel Dev 2001; 34:39-55.

73. Ritz SA, Antle DM, Côté J, Deroy K, Fraleigh N, Messing K, Parent L, St-Pierre J, Vaillancourt C, Mergler D. First steps for integrating sex and gender considerations into basic experimental biomedical research. FASEB J 2014;28:4-13.

74. Doull M, Runnels VE, Tudiver S, Boscoe M. Appraising the evidence: applying sex- and gender-based analysis (SGBA) to Cochrane systematic reviews on cardiovascular diseases. J Womens Health (Larchmt) 2010;19:997-1003.

75. Kop WJ, Everson-Rose SA. The editors respond. Psychosom Med 2015;77:1068-9.

76. Orth-Gomer K, Deter HC. Sex and gender issues in cardiovascular research. Psychosom Med 2015;77:1067-8.

77. Mauss D, Li J, Schmidt B, Angerer P, Jarczok MN. Measuring allostatic load in the workforce: a systematic review. Ind Health 2015;53:5-20.

78. Hammarström A. A tool for developing gender research in medicine: examples from the medical literature on work life. Gend Med 2007;4:S123-32.

79. Johnson JL, Greaves L, Repta R. Better Science With Sex and Gender: A Primer of Health Research. Canadian Institutes for Health Research Institute of Gender and Health: Ottawa; 2007.

80. Joel D, Berman Z, Tavor I, Wexler N, Gaber O, Stein Y, Shefi N, Pool J, Urchs S, Margulies DS, Liem F, Hanggi J, Jancke L, Assaf Y. Sex beyond the genitalia: the human brain mosaic. Proc Natl Acad Sci U S A 2015;112:15468-73.

81. Juster RP, Lupien SJ. Sex and gender in stress research: the metamorphosis of a field. In: IGH, ed. What a Difference Sex and Gender Make: A Gender, Sex and Health Research Casebook. Vancouver: Canadian Institutes for Health Research Institute of Gender and Health; 2012. 